\title{
Verdad y posverdad en la crítica periodística. Caso: Daniel Urresti y las lecciones del $2018^{1}$
}

\section{True and post-truth in journalistic criticism. Case: Daniel Urresti and the lessons of 2018}

Recibido: 24/08/2020

Aceptado: 10/04/2021

Publicado: 30/06/2021
Carla Andrea Portocarrero Reggiardo u20141a358@upc.edu.pe https://orcid.org/0000-0002-6156-1026

Universidad Peruana de Ciencias Aplicadas (Perú)

Resumen: Dentro del periodismo existen notas críticas e informativas. En estas últimas, el lector espera encontrar información y un enfoque equilibrado, para así formar su propia opinión. Sin embargo, en el Perú, durante las elecciones municipales de 2018, en el caso concreto del diario El Comercio respecto a la candidatura de Daniel Urresti, no fue así. De las 62 notas informativas publicadas sobre Urresti, cinco de ellas fueron, en realidad, notas críticas, lo que pudo influir en los lectores al momento de tomar posición. El presente artículo analiza tres de estas cinco notas. El criterio de selección ha sido la presencia de un mayor énfasis crítico, así como un uso ampuloso de los mecanismos de la posverdad. La conclusión principal es que estos mecanismos de posverdad evidencian, más que la intensión de informar, el objetivo de criticar e indirectamente influir en los lectores al momento de evaluar la candidatura de Urresti.

Palabras clave: Posverdad, Discurso, Ideología política, Periodismo, Poder.

1. El artículo es un avance de la tesis de licenciatura titulada "Discurso periodístico y posverdad en los diarios La República y El Comercio durante las elecciones municipales de Lima Metropolitana. Casos: Ricardo Belmont y Daniel Urresti” (2020). De la Universidad Peruana de Ciencias Aplicadas (UPC). 
Abstract: Within journalism there are critical and informative notes. In the latter the reader hopes to find information and a balanced approach in order to form his own opinion. However, in Peru, during the municipal elections of 2018, in the case of the newspaper El Comercio regarding the candidacy about Daniel Urresti, it was not. Of the 62 briefing notes published on Urresti, five of them were, in fact, critical notes, which could influence readers when taking a position. This article analyzes three of these five notes, the selection criterion was the presence of a higher critical emphasis and a turgid use posttruth mechanisms. The main conclusion is that these mechanisms post-truth evidence, more than the intention of informing, the objective of criticizing and indirectly influencing readers when evaluating Urresti's candidacy.

Key words: Post-truth, Speech, Political ideology, Journalism, Power.

\section{Introducción}

El presente artículo abordará la crítica periodística a la candidatura de Daniel Urresti realizada por el diario El Comercio entre el 24 y el 29 de setiembre de 2018, en el marco del proceso electoral municipal de Lima. Estas fueron unas elecciones controversiales en las que participaron 21 candidatos, quienes deseaban la atención de los medios de comunicación. Sin embargo, los postulantes que recibían más cobertura por parte de los diarios eran los que obtenían los primeros puestos en las encuestas. Uno de ellos fue Daniel Urresti, quien, en las publicaciones de la versión digital de El Comercio, era criticado de manera constante. Por ello, se desea saber cuál es el discurso periodístico que empleó dicho diario y de qué manera la posverdad se manifestó en las elecciones municipales.

En la presente investigación se enfatiza en una serie de conceptos. Uno de ellos es el término de discurso periodístico, que, según Van Dijk (2009), es una práctica social o un acto lingüístico. Se comprende que el discurso es un recurso fundamental del poder. Entonces, el periodista tiene poder en la información, a diferencia de los ciudadanos, porque posee información de primera mano, brindándola a los ciudadanos. Es decir, tiene un acceso preferencial al discurso público.

Por otro lado, el concepto de posverdad, según Fowks (2017), está presente en el discurso periodístico, debido a que los medios desinforman las característi- 
cas delos candidatos. Además, de acuerdo con Califano(2015), existen diversos acontecimientos públicos queno necesariamente son noticias. Es decir, el medio de comunicación hace una selección de temas según la realidad parcializada o la línea editorial que tenga, en donde se considera a la noticia como subjetiva. Por ello, los medios son actores políticos, ya que se comprometen en los hechos políticos al extremo de que toman una posición conveniente para sí mismos.

Por último, Barrios \& Hernández (2011) señalan que debe existir equilibrio informativo en los medios de comunicación. En otras palabras, los 21 postulantes a la alcaldía de Lima, capital de Perú, deben tener el mismo tiempo y espacio para difundir sus propuestas; pero lo manifestado no es accesible, porque los medios brindan privilegios solo a algunos candidatos.

\section{Marco teórico y contextual}

\subsection{El discurso público}

Van Dijk (2009) define este concepto como una construcción multimedia manifestada en gestos, sonidos, imágenes, palabras y música. También, señala el autor, se le conoce como un acto lingüístico y una práctica social. Por lo tanto, el discurso está presente hasta al inventar algo, ya que se utiliza la mente para tal discurso.

De otro lado, los periodistas controlan la mente de las personas a través del discurso que realizan en su cobertura. Emplean técnicas como manipulación, censura y persuasión. De esta manera, este miembro que labora en la prensa sabe que puede cambiar la visión, normas o valores que tiene el público respecto a un determinado tema. Por ello, el poder que emplean los periodistas se concluye como acceso activo y controlador en la manera como escribe su texto (Van Dijk, 2009).

\subsection{Tratamiento de la información y construcción del discurso}

Van Dijk (2009) manifiesta que la noticia debe considerarse como una forma de discurso público, ya que la investigación que realizan los periodistas se evidencia en una comunicación de masas, interpretándola desde dimensio- 
nes sociales, culturales y económicas. Asimismo, afirma el citado autor, la información que brinda la prensa anhela a describir los acontecimientos con precisión y exactitud, empleando fuentes fiables para que testifiquen lo que sucedió en ese momento. Es común que las citas directas sean una técnica para demostrar que la noticia tiene fundamento.

De otro lado, para que la noticia tenga más acogida, apela a proporcionar información vinculada con las emociones, así como a citar fuentes de opinión que tengan una ideología diferente y controversial. Con esto se puede ver que la prensa no es un mediador neutral, lógico o racional de lo que sucede socialmente, sino que, lo que hace, es producir ideologías reformuladas (Van Dijk, 1990).

En conclusión, las ideologías están vinculadas con las representaciones cognitivas que parten de la forma en que se produce y comprende la noticia en los medios de comunicación. Por ende, la prensa es independiente en la manera como se reproduce culturalmente, pero sí resulta dependiente de ideologías sociales más extensas (Van Dijk, 1990).

Por otro lado, Feal Vázquez (2004) refiere que la información, hoy en día, es percibida como una mercancía, es decir, de tipo comercial. Se compra y vende la información con el fin de beneficiarse. También, manifiesta que la información está acelerada, pues los periodistas priorizan la rapidez y lo instantáneo en cuanto a la publicación de una noticia, en detrimento de estudiarla detalladamente. Otra característica importante, para el mencionado autor, es que la información generalmente es gratuita. Por ejemplo, cuando los noticieros informan sobre aquellas noticias ricas en información, lo hacen abiertamente; es decir, no reciben pago por ello. Feal Vázquez (2004) menciona que quien paga la información es la publicidad.

\subsection{La nota informativa}

Diversos autores definen lo que, para ellos, significa una nota. Sin embargo, todos los exponentes analizados coinciden en que la nota es un acontecimiento que va a suceder o que, de lo contrario, ya ocurrió. Se entiende como una noticia que debe ser contada como un hecho verdadero que tenga interés general para su máxima difusión a un público masivo. Asimismo, este artículo considera que la noticia debe ser contada empleando las preguntas típicas: 
¿qué?, ¿quién?, ¿cómo?, ¿cuándo?, ¿dónde? y ¿por qué?; y que, al responder estos cuestionamientos, se entiende que la noticia tiene una información completa. Generalmente se acostumbra a priorizar la información en los primeros párrafos del texto y luego se desarrolla el suceso con datos secundarios, dependiendo del espacio y el tiempo disponibles a los que se adecúa el periodista. Es decir, en la mayoría de casos se emplea la pirámide invertida. En la entrada, por ejemplo, el lector se crea una idea de lo que quiere saber de manera general (Moreno, 2000).

\subsection{El periodismo político}

\subsubsection{Relevancia social de los medios en procesos electorales}

Casero-Ripolles (2012), en su proyecto de investigación, manifiesta que el periodismo político se desenvuelve en temas derivados de los gobiernos, partidos políticos, las elecciones, entre otros. Tiene una mirada a la política institucional y a la extrarepresentativa que se origina en manifestaciones o enfrentamientos netamente influenciados en la sociedad civil. Esta práctica informativa, al estar dentro de un régimen democrático, posee más relevancia en la profesión periodística. Por esta razón, las noticias de ese rubro tienen una numerosa visibilidad en los medios.

Existen cuatro factores que limitan el ejercicio del periodismo político en términos globales: la mediatización de la política, la profesionalización de la comunicación política, la mercantilización de la prensa y la digitalización (Casero-Ripolles, 2012). Morán \& Aguirre (2014), por su parte, comentan que la prensa escrita, en cada país, desarrolla puntos de vista, argumentos y aspectos más relevantes de lo que sucede en la sociedad que la contempla. Por ello, se analiza el discurso que emplean los medios peruanos y cómo este se relaciona con el poder político.

El texto, también, plasma que el periodista es una persona que pertenece a una clase social específica, motivo por el cual no puede ser indiferente de sus afinidades. Por ende, al publicar sus respectivas noticias en los medios, no solo informa lo que pasa en la vida diaria, sino también elabora un discurso que genere interés y apoyo a la clase social con la que está involucrado. Según Morán \& Aguirre (2014), es incorrecto creer que el periodista solo informa lo que sucede en la vida diaria, siendo totalmente imparcial; al contrario, los periodistas son 
portavoces de la ideología dominante. Por ende, si el periodista pertenece a determinada organización política, elaborará un escrito a favor de este.

De otro lado, García (2009) menciona que la prensa debe ser imparcial y balanceada al momento de informar, sin priorizar a ciertos candidatos. Sin embargo, existen medios gubernamentales que no cumplen la misma función que realizan los organismos electorales. El autor recomienda que estas dos organizaciones deben estar complementadas, para que se pueda brindar información independiente y de calidad. Asimismo, advierte que los medios, al solo referirse sobre un político o partido, no necesariamente quieren decir que exista un apoyo absoluto a tal organización o candidato. Cabe la opción que ese funcionario público tenga más cobertura porque realiza más actividades que los demás. Otro aspecto relevante que menciona es que las encuestas que realizan o difunden los medios de comunicación influyen en la opinión pública. La prensa, al conocer qué temas debe exponer, saca provecho de ello y lo evidencia consecutivamente.

García (2009) también comenta sobre la ayuda que internet aporta a los electores. Para citar un caso, en Chile y Panamá se han estrenado programas tecnológicos para que los votantes puedan tener más información acerca del día de la votación. Por ejemplo, "datos del lugar de votación, horarios, mapas, disposición de las mesas receptoras de sufragios y otras noticias electorales" (p.8).

Actualmente, en las sociedades, la preocupación de los medios es transformar las ideas del grupo dominante en lo que se consideraría "normal", con el objetivo de conservar y priorizar esa situación. Asimismo, la política es un espectáculo, entendiéndola como un escenario al que pertenecen actores y que estos, a su vez, se exhiben en los medios. Por lo tanto, al no mostrarse en los medios tampoco pertenecerían a la política. Es decir, el escenario de la política son los medios (Béjar et. al., 2008).

En los medios se quiere influenciar a los lectores o televidentes sobre qué es lo adecuado y qué es lo rechazable. Se considera a la audiencia como un grupo de menores de edad, quienes no tienen la posibilidad de saber la "verdad" por sí solos y que necesitan ayuda de la prensa para informarse. Por ello, los medios, al decir las cosas, desean construir temor y eligen cuáles son los enemigos para realizar el linchamiento mediático. Vale mencionar que los medios, al ignorar o enfatizar un determinado tema, están realizando un poder de elección que no poseen los ciudadanos (Béjar et al., 2008) 
Por su parte, Adrianzén et al. (2008) cuentan que no todo hecho es percibido como acontecimiento, pues el servidor público es quien lo define. Según el autor, la política es, en general, comunicación. Se entiende que existe una realidad a nuestro alrededor y que uno supuestamente la describe "neutralmente". Sin embargo, esto es discutible. Asimismo, la complejidad del Perú es que no existe un control ciudadano en la prensa, como sí lo hay en otros países como Argentina, que cuenta con una institución estatal llamada Observatorio de la Discriminación en Radio y Televisión, basada en percibir los grados de discriminación que se presentan en los medios. Es decir, en el Perú no existen mecanismos de fiscalización donde se supervise la función de un medio. La idea es que los derechos de las personas no se vean perjudicados por la libertad de prensa (Adrianzén et al., 2008).

En conclusión, cada medio elabora su propio acontecimiento, según los cálculos que realizan políticamente; por lo que se puede decir que cada medio realiza lo que desea, según su conveniencia (Adrianzén et al., 2008).

\subsubsection{La importancia de los temas en el discurso público}

Para Van Dijk (2005) los temas en el discurso público son relevantes en todo el sentido de la palabra, ya que si un ciudadano o grupo de personas pueden controlar los temas que se exponen, entonces estarán teniendo en su poder el discurso de lo que piensa la gente. El prejuicio, por ejemplo, se construye enfatizando lo negativo de las sociedades, razón por la cual nacen las ideologías. Por lo tanto, los medios de comunicación no se refieren inapropiadamente sobre un determinado tema, solo priorizan más los que generen controversia.

Van Dijk (2009), además, manifiesta que la ideología y el discurso se evidencian mayormente en temas relacionados con la política, debido a que en tales discursos políticos uno puede manifestar sus opiniones formulando ideas sin dejar de lado que estas sean "observables". Para el autor, los grupos minoritarios también tienen ideologías. Es decir, no solo los grupos dominantes cuentan con ello, porque en toda organización donde exista intercambio de ideas y acuerdos se están evidenciando los intereses básicos y necesarios de las personas. 


\subsection{La posverdad}

\subsubsection{Verdad y posverdad}

El diccionario de Oxford eligió a la posverdad como palabra del año en 2016. La define como "circunstancias en que los hechos objetivos influyen menos en la formación de la opinión pública, que los llamamientos a la emoción y a la creencia personal".

Bajo este criterio, Frápolli \& Nicolás (1997) sostienen la existencia de siete teorías de la verdad: las pragmáticas, las de correspondencia, las prooracionales, las fenomenológicas, las hermenéuticas, las coherenciales y las intersubjetivistas. De todas estas perspectivas se deduce que al término verdad se le considera como "lo que está presente", "lo que está patente" y "lo que merece confianza". Así pues, lo verdadero también está relacionado con características que brinden seguridad y firmeza.

Por otro lado, Copi \& Cohen (2013) explican que las falacias son una manera de argumentar algo que parece válido o correcto, pero que al analizarlo no lo es. Estas, según los autores, tienen cuatro categorías: falacias de relevancia, falacias de inducción deficiente, falacias de presuposición y falacias de ambigüedad. La primera de ellas se basa en supuestos que parecen importantes para la conclusión realizada, pero que finalmente no lo son. Las seis falacias de este tipo son las siguientes: apelación a la emoción, la pista falsa, el hombre de paja, la apelación a la fuerza, el argumento ad hominem (ofensivo o circunstancial) y la conclusión irrelevante.

La segunda categoría de falacia, la de presunción, se basa en que las hipótesis pueden ser relevantes para la conclusión, pero son frágiles. Los cuatro tipos de esta categoría son la apelación a la ignorancia, la apelación inapropiada a la autoridad, la causa falsa y la generalización precipitada (Copi \& Cohen, 2013). La tercera categoría se basa en confiar en una proposición que parece ser verdadera en su argumento, pero que finalmente no lo es, porque no tiene justificación y es falsa. Estas se subdividen en falacias por accidente, una pregunta compleja y una petición de principio (Copi \& Cohen, 2013).

La cuarta y última categoría, la de ambigüedad, se basa en la modificación que se realiza en el significado de palabras o frases, o sea de los significados que poseen los supuestos a significados heterogéneos que tienen las con- 
clusiones. Esta categoría se clasifica en la equivocación, la anfibología, el acento, la composición y la división. Entonces, según los citados autores, las falacias que se utilizarían en la posverdad serían cuatro: la de relevancia, la de inducción deficiente, la de presuposición y la de ambigüedad (Copi \& Cohen, 2013).

Siguiendo con Copi \& Cohen (2013), la falacia de relevancia significa que los argumentos ambiguos pueden parecer importantes, mas no lo son. Esta se divide en tres características aplicables en la campaña electoral. La primera es la pista falsa, que tiende a darse cuando un pensamiento correcto es modificado a causa de la intromisión de algún personaje o hecho que provoca un cambio de atención. La segunda es la apelación a la fuerza, cuando el pensamiento correcto, bajo fuerza mayor, es impuesto a aceptar cambios o llegar a diferentes conclusiones.

El tercero es el argumento ad hominem, cuando se procede a atacar directamente a la persona, mas no a las afirmaciones que esta hace. Se distinguen dos subtipos que son ad hominem ofensivo y ad hominem circunstancial. El primero se origina cuando el ataque es directo e intenta difamar o desacreditar al defensor de una postura; mientras que el segundo se desarrolla cuando el ataque es indirecto y sugiere que el defensor de alguna postura mantenga ese punto de vista debido a circunstancias o intereses especiales (Copi \& Cohen, 2013).

Del mismo modo, la falacia de inducción deficiente significa que las hipótesis pueden ser importantes para la conclusión, pero tienden a ser demasiado débiles para apoyar a la conclusión a la que se ha llegado. Esta se divide en dos características aplicables en la campaña electoral. La primera es la apelación inapropiada a la autoridad, que se da cuando las hipótesis son respaldadas por individuos que no tienen una autoridad legítima como expertos en el tema en cuestión. La segunda es la generalización precipitada, que es cuando se pasa de forma descuidada de uno o muy pocos casos a una afirmación universal o general (Copi \& Cohen, 2013).

Por su lado, la falacia de presuposición se da cuando el problema surge por confiar en alguna proposición, que se comprende como verdadera, pero no tiene justificación y es falsa o dudosa. Esta se divide en tres características aplicables en la campaña electoral. La primera, "de accidente", se aplica erróneamente a una generalización de un caso particular en el que no pro- 
cede adecuadamente. La segunda, de "pregunta compleja", que se justifica haciendo una pregunta que presupone la verdad de algún supuesto oculto en el cuestionamiento. La tercera, de "petición de principio", percibida en que las hipótesis se aceptan y entienden como la verdad de lo que uno intenta establecer en la conclusión de ese mismo argumento (Copi \& Cohen, 2013).

Se entiende por falacia de ambigüedad a la situación que se presenta cuando la equivocación surge como resultado del cambio del significado de palabras (es decir, los significados que tienen en las premisas) a significados diferentes que tienen en las conclusiones. Esta falacia se divide en cuatro características aplicables en la campaña electoral. La primera es la de anfibología, que se da cuando en uno de los enunciados un argumento tiene más de un significado, esto debido a la manera incorrecta en la que se han combinado las palabras en ese enunciado. La segunda es la de acento, que ocurre cuando existe un cambio de significado en un argumento y como consecuencia de las modificaciones de énfasis dado a las palabras o partes (Copi \& Cohen, 2013).

La tercera es la de composición, que se origina cuando se piensa de forma equivocada a partir de los atributos de una parte a los atributos del todo, o cuando se concluye erróneamente a partir de los atributos de una persona de algún grupo a los atributos de la totalidad. La cuarta es la de división, que se presenta cuando se razona incorrectamente a partir de características de una totalidad a características de una de sus partes o cuando se piensa erróneamente a partir de las propiedades de elementos grupales a las propiedades de los elementos individuales (Copi \& Cohen, 2013).

\subsubsection{Los mecanismos de la posverdad}

\subsubsection{La desinformación}

La posverdad se basa en desinformar a los ciudadanos basándose en las creencias y emociones, teniendo un objetivo político o económico. Es decir, no existe posverdad si no hay novedad. También, los canales y diarios "sitúan la información de acuerdo a fines particulares, conforme a un interés, ya sea para informar o desinformar" (Fowks, 2017, p. 33). Vale recalcar que actualmente las personas, con el uso de internet y de los medios de comunicación, pueden informar o desinformar fácilmente con gran capacidad de llegada y viralización (Fowks, 2017). 
La prensa, en su deseo de publicar todo acontecimiento de manera rápida, puede caer en rumores que solo traen consigo preocupaciones en las personas. Los medios han recurrido a sobrellevar prácticas periodísticas cuestionables como, por ejemplo, los generadores "no profesionales". Una situación particular que proporciona Fowks (2017) es que el periodista, al utilizar en una nota informativa la frase "según se supo", está haciendo uso de información no verificada, ya que no evidencia la fuente de información, por lo que existe un evidente bloqueo informativo.

\subsubsection{Hechos alternativos}

Para Fowks (2017), los hechos alternativos son argumentos creados para refutar los datos reales y evidentes. Estos hechos son utilizados por la mayoría de los políticos, con el propósito de confundir al público y, a su vez, confrontar lo que manifiesta el candidato opositor. Por lo tanto, existe una desinformación en lo que exponen los medios de comunicación.

Los periodistas, al redactar sus notas informativas o artículos, se dejan llevar por los sentimientos, más que por lo verídico, sobre todo en temas coyunturales como las elecciones en cualquiera de sus modalidades. Por ello, al cumplir la función de informadores, no dicen las cosas completas, pues "se limitan a reproducir lo que las fuentes dijeron" (Fowks, 2017, p.65). Bajo estas percepciones se puede ver que la noticia no está preparada para darla a conocer. No obstante, los periodistas igual la publican y se ponen en contacto con la fuente de información, para manipularla con intereses políticos, económicos o fácticos (Fowks, 2017).

Asimismo, Kovach \& Rosenstiel (2003) comentan que existen nueve elementos del periodismo que deben estar presentes al momento de redactar un texto periodístico, para no caer en hechos alternativos. Por ello, parten de la definición de lo que es periodismo: "el medio que la sociedad ha creado para suministrarnos esa información. Por eso, nos importa tanto la esencia de las noticias y del propio periodismo" (p. 14).

Los elementos mencionados son los siguientes: el primero es que el periodista siempre debe decir la verdad; el segundo es que debe ser leal a lo que informa; el tercero responde a la verificación de todo acontecimiento que suceda; el cuarto trata de la independencia del periodista de cualquier 
casa editorial o televisiva; el quinto es que el periodista no debe depender del poder; el sexto afirma que el periodismo debe promover la opinión entre ciudadanos; el séptimo se basa en que el periodista debe hacer que el significante sea importante; el octavo es que el periodista debe formar una noticia que sea exhaustiva y proporcionada; $y$, finalmente, el noveno consiste en que se respete el criterio y conciencia de cada servidor público (Kovach \& Rosenstiel, 2003).

Además, para que una colectividad pueda autogobernarse sin necesidad de intereses políticos o económicos, los autores comentan que el periodismo honra a la sociedad una "información independiente, veraz, exacta y ecuánime que todo ciudadano necesita para ser libre" (Kovach \& Rosenstiel, 2003, p. 7).

A su vez, la Fundación Gabo (2019) rescata las diez aptitudes que, para Javier Darío Restrepo, debe tener un buen periodista. En primer lugar, este servidor público debe ser buena persona. Los buenos editores, por ejemplo, deben exponer sus experiencias, corroborar sus conocimientos y establecer un ambiente favorable para el ejercicio de esta profesión. Asimismo, para un periodista todo tema debe ser bueno si la manera como lo trata no compromete quebrantar los derechos de las personas, sino, al contrario, respetarlos.

En segundo lugar, el periodista debe estar orgulloso de su carrera. Es decir, conocer los riesgos que conlleva esta profesión sin tener temor. Al contrario, lo que se debe tener es entusiasmo y pasión para servir al público. En tercer lugar, este debe tener un sentido de misión en su ejercicio profesional. En otras palabras, el periodismo sirve para informar y resguardar a los electores del engaño del poder. También, el periodismo tiene el objetivo de que las personas conozcan las cosas tal cual son, preservando el interés del bien común. En cuarto lugar, debe ser apasionado por la verdad, esa que signifique la fidelidad a los hechos sobre los que informa constantemente. En quinto lugar, debe ser autocrítico. La rectificación de un error, por ejemplo, es un deber del medio periodístico y un derecho del receptor. Asimismo, no debe ser sumiso ni obediente, al contrario, debe desarrollar sus ideas con independencia. En sexto lugar, debe realizar y compartir los conocimientos. Al obtener información, la procesa para transformarla en conocimiento y la divulga eficientemente. En séptimo lugar, debe producir periodismo con un fin. El objetivo es informar a la sociedad, sin ser identificado con algún partido, así como proteger al elector de los intentos propagandísticos. En octavo lugar, debe tener sentido en el otro. Es decir, la conciencia ética está presente al poner como 
primera opción al otro. Asimismo, este servidor público debe ponerse en el lugar del otro para aceptar las circunstancias y evitar los agravios. En noveno lugar, debe ser independiente. No se informa siguiendo los criterios del medio de comunicación, al contrario, se comunican los hechos tal cual ocurren sin ánimos de distorsionarlos; esto con el objetivo de tener la confianza del público lector. En décimo y último lugar, debe conservar íntegra su capacidad de asombro. No puede estar familiarizado a tareas mecánicas donde se limite únicamente a exponer y hacer oír, sino que el receptor debe entender e involucrarse en los sucesos (Fundación Gabo, 2019).

Clavero (2018) establece lo que significa posverdad, vista desde un panorama sociocultural. Además, comenta cómo las fake news repercuten en el periodismo y en el público lector. El término de posverdad no está aislado, tiene que ver con una serie de sucesos que se complementan y que sobrepasan el debate público moderno. Asimismo, este autor manifiesta que los medios están más preocupados en exponer una noticia de manera veloz que de manera verídica. Por ello, existe una sobrecarga de textos periodísticos basados en mentiras u omisiones.

Clavero (2018) detalla un inconveniente, pues dice que no existen las condiciones apropiadas en la esfera pública para decretar lo que es verdad. Ante este escenario, el autor propone dos fuentes de convergencia: la crisis de los medios tradicionales que afecta a la actividad periodística y la proliferación de internet, que se reproduce en grandes proporciones sin saber qué información es real. Por ello, la posverdad y las fakes news se desarrollan en esta última fuente. La posverdad se aleja de los deseos objetivos y previsibles, sin embargo, las redes sociales han contribuido a que exista más diversificación de la información de manera pública. Por ello, las fakes news no son controladas en su totalidad por estados o medios, sino que son las mismas personas que se dedican a crear grupos de usuarios para multiplicar noticias falsas. En resumen, se puede decir que los periodistas o profesionales no son los únicos responsables de que exista posverdad, también las personas tienen responsabilidad en ello.

González (2017), en "La posverdad en el plebiscito por la paz en Colombia", informa que ganó el "No" debido a que los discursos se basaron en el miedo, la guerra y el comunismo, particularidades que desataban una ola de comentarios en las redes sociales, como Twitter y Facebook. Sin embargo, las noticias que se publicaban en estos medios no siempre eran de buena calidad, debido 
a la rapidez con la que eran difundidas. Por ello, se dudaba de la veracidad de sus notas. Esto recurría a que se emplee el término de posverdad invocada por la emoción y creencias personales.

Asimismo, la autora cuenta sobre una entrevista que realizó el periódico Le Monde, en donde un profesor manifestaba que la baja confianza de los pobladores en la prensa, y el uso de campañas de rumor, hacían que se tenga menos credibilidad en las noticias. El principal motivo era exponer noticias que los ciudadanos querían escuchar, no lo que realmente pensaban los candidatos políticos (González, 2017).

\subsubsection{Interpretaciones alternativas}

Existen innumerables hechos que han sucedido a lo largo de la historia, pero a partir de estos las personas tienen diferentes interpretaciones sobre ellos. Esto quiere decir que los sucesos no se ponen en tela de juicio, ya que son evidentes, sin embargo, se conocen de manera diferente (El Popular, 2020).

Por ejemplo, el 15 de abril de 2020, miles de peruanos percibieron que en el cielo había una luz extraña y movediza. La Administración Nacional de la Aeronáutica y del Espacio (NASA) confirmó que era una lluvia de meteoritos, pero para los pobladores peruanos, especialmente iqueños, eran ovnis que habían venido a observar la tierra, mientras que para el meteorólogo Abraham Levy se trataba de "material suelto", similar a grandes rocas que pueden ser restos de cometas (El Popular, 2020).

Al respecto, Alpizar (2018) detalla cuál debe ser el proceso para analizar la información que se expone en un medio de comunicación. Primero, uno debe dudar, planteándose preguntas que muestren si la afirmación es verídica o falsa. Con esto se encontrarán posibles respuestas. Esta herramienta permite que no se acepte la información acríticamente, al contrario, exige que se presente con una evidencia apta para acreditarla. Segundo, se debe investigar, buscando heterogéneas fuentes de información que testifiquen la noticia. Por ejemplo, conocer dónde sucedió, en qué momento, cómo y por qué se desarrolló tal acontecimiento. Tercero, se debe analizar cada segmento de la noticia. Es decir, cómo se compone y el lenguaje que se emplea 
en tal discurso. Por lo tanto, realizar estos tres mecanismos podrá ayudar al lector a diferenciar un hecho ficticio de uno real, así como a emplear el pensamiento crítico.

La autora también comenta un ejemplo en el que menciona que Venezuela vive una crisis humanitaria y que el presidente Nicolás Maduro es un dictador. Si bien el hecho es uno solo y se sabe que el país vecino está pasando por problemas con su autoridad, para cada venezolano existe una "realidad" distinta, la cual tiene una interpretación diferenciada. Para unos el gobernador es un absolutista y para otros no, por eso es importante informarse tanto de las opiniones positivas como de las negativas. Todo dependerá de lo que atraviesa esa persona en ese país y de la ideología que tenga para realizar afirmaciones. Además, la redactora dice que se debe tener cuidado con cada término empleado o dicho, pues muchas veces se tiene un concepto errado de lo que se revela (Alpizar, 2018).

Mittermeier (2017) comenta que la posverdad involucra a distintos actores sociales envueltos en la opinión pública, mientras que la mentira es solo un acto locutivo con información falsa. También dice que la posverdad empieza generalmente en temas políticos y eso trae consigo que los periodistas realicen noticias guiadas por las emociones y creencias del momento.

Uno de los aspectos que la citada autora anuncia es que se puede conocer un hecho que es verídico y conciso, sin embargo, la ciudadanía prefiere escuchar o hacerle caso a los aspectos más interesantes y controversiales de ese mismo suceso. Esto trae consigo que lo que se supo se distorsione y transforme, pues se opta por los estereotipos y prejuicios en busca de atención. Por ello, existen una serie de interpretaciones a un solo incidente, entendiéndolas como alternativas. Parte de que la población crea en lo superficial y no en el contenido en sí es porque, al estar saturada de información, prefiere lo aparente, es decir, lo creíble. Se conforma con su intuición, por lo que la emoción juzga la información (Mittermeier, 2017).

\section{Metodología}

La presente investigación es de carácter aplicado, ya que se busca resolver un caso o problema práctico aplicando la teoría existente. El nivel de la inves- 
tigación es descriptivo, porque se busca describir las notas informativas del medio El Comercio para poder percibir los aspectos negativos que ocurrieron en las elecciones municipales en cuanto al candidato Daniel Urresti.

El diseño es no experimental y, a su vez, cualitativo, porque no se manipula la realidad o las variables presentes, pues el hecho, como la contienda electoral, es pasado. También, es cualitativo debido a que se identifican y se analizan los discursos que el diario publica en esas tres notas informativas. La técnica e instrumento de recolección de datos es análisis de contenido, mientras que el instrumento que se utiliza es la matriz de análisis.

Por otro lado, el universo son las notas informativas del diario El Comercio sobre el candidato Daniel Urresti, durante la campaña electoral a la alcaldía de Lima en el mes de setiembre de 2018. Asimismo, el análisis se realizó en el último mes de la campaña electoral, es decir, en el mes de setiembre, porque al estar cerca del día de las votaciones ( 07 de octubre) se evidenció más atención en el tema. Por ende, las notas informativas del diario mostraban una posición mucho más crítica hacia el candidato en cuestión.

Respecto a la población y muestra, se realiza el análisis de contenido de las tres notas informativas que provee el diario en particular durante el último mes que duró la campaña electoral. En total, serán tres notas informativas donde la población es igual a la muestra. Si bien, en total, fueron más notas (62 del diario El Comercio para Daniel Urresti), el tema de investigación es cómo se construyó la crítica del mencionado diario a dicho candidato y, aplicando dicho criterio, solo existen tres notas en el mes de setiembre. 


\section{Resultados}

\subsection{Publicación realizada el 24/09/18}

\section{Tabla 1}

\section{Contenido del diario El Comercio}

\begin{tabular}{|c|c|}
\hline Fuente & $\begin{array}{l}\text { https://elcomercio.pe/politica/daniel-urresti-evita-precisar-renuncia- } \\
\text { ra-candidatura-caso-sea-condenado-noticia-561024-noticia/?ref=ecr }\end{array}$ \\
\hline Titular & $\begin{array}{l}\text { "Urresti evita precisar si renunciará a candidatura en caso sea condena- } \\
\text { do" }\end{array}$ \\
\hline $\begin{array}{l}\text { Sentido del } \\
\text { titular }\end{array}$ & $\begin{array}{l}\text { Se pone especial énfasis en conocer si Daniel Urresti renunciaría como } \\
\text { postulante a la alcaldía de Lima, mas no prioriza el crimen que sucedió } \\
\text { en } 1988 \text { con el caso Bustíos. Se desea demostrar que el silencio otorga } \\
\text { en el caso del candidato, pues está la opción que si Urresti es condenado } \\
\text { puede que no renuncie y eso sería de desagrado para los ciudadanos. }\end{array}$ \\
\hline Bajada & $\begin{array}{l}\text { "El postulante de Podemos Perú a la alcaldía de Lima dijo que no se pone } \\
\text { en ese escenario, pues confía en ser absuelto en el Caso Hugo Bustíos" }\end{array}$ \\
\hline $\begin{array}{l}\text { Sentido de la } \\
\text { bajada }\end{array}$ & $\begin{array}{l}\text { Evidenciar que el candidato Daniel Urresti está sumamente confiado y } \\
\text { tranquilo, que el día del juicio será absuelto. Sin embargo, esa seguridad } \\
\text { no es real, ya que también está la opción que sea condenado. }\end{array}$ \\
\hline $\begin{array}{l}\text { Cuerpo de } \\
\text { texto }\end{array}$ & $\begin{array}{l}\text { "El candidato de Podemos Perú a la alcaldía de Lima, Daniel Urresti, } \\
\text { evitó precisar si renunciará a su postulación en caso reciba una senten- } \\
\text { cia condenatoria este } 4 \text { de octubre. Ese día se conocerá el veredicto del } \\
\text { Colegiado B de la Sala Penal Nacional del Poder Judicial sobre el pro- } \\
\text { ceso por el asesinato del periodista Hugo Bustíos, ocurrido en } 1988 \text { en } \\
\text { Ayacucho. } \\
\text { En una entrevista con El Comercio en mayo pasado, Urresti sí se puso } \\
\text { en ese escenario y ante la pregunta sobre si retirará su candidatura en } \\
\text { caso sea condenado, respondió: Por su puesto, ni qué dudarlo, pero eso } \\
\text { es remoto. Pero en el extremo de que eso suceda, sí por supuesto que la } \\
\text { retiraría de inmediato". } \\
\text { Consultado al respecto este lunes por este Diario, el también ex ministro } \\
\text { del Interior sostuvo: "El escenario era que si mi sentencia salía después } \\
\text { del } 7 \text { de octubre, yo renunciaba. No va a salir después del 7, sale el } 4 \text {, } \\
\text { tres días antes de las elecciones. Entonces, el día de las elecciones van a } \\
\text { poder ir a votar con la tranquilidad de saber que soy inocente". } \\
\text { Precisamente la defensa de Daniel Urresti dio sus alegatos finales en el } \\
\text { juicio. El candidato dijo que se desbarataron las hipótesis de la fiscalía y } \\
\text { que su inocencia ha quedado totalmente demostrada. }\end{array}$ \\
\hline
\end{tabular}




\begin{tabular}{|c|c|}
\hline & $\begin{array}{l}\text { "Yo no me pongo en escenarios que para mí no son reales. El día } 4 \text { yo } \\
\text { voy a ser absuelto, lo voy a celebrar a lo grande", aseveró también. } \\
\text { En esa línea, insistió en que para él no cabe la posibilidad de la condena, } \\
\text { por eso evitó ponerse en un eventual escenario en el que tenga que re- } \\
\text { nunciar a su candidatura. } \\
\text { "Es imposible que yo haya podido estar siquiera cerca de lugar donde } \\
\text { sucedió el asesinato. Por lo tanto, yo voy a presentar una prueba más el } \\
\text { día que me toca mi defensa personal y el } 4 \text { de octubre lo que va a suceder } \\
\text { es que me van a absolver. No hay forma de que me condenen", ratificó. A } \\
\text { su juicio, de ser ese el caso, más ciudadanos se animarían a votar por él. } \\
\text {-Lo que dice la norma- } \\
\text { El reglamento del Jurado Nacional de Elecciones (JNE) de inscripción } \\
\text { de listas de candidatos para las elecciones estableció que vencido el } \\
\text { plazo de exclusión de candidatos por cuestionamientos a su hoja de vida } \\
\text { y procesos por dádivas -ocurrió el pasado } 7 \text { de setiembre-, el JEE } \\
\text { puede aún disponer de oficio la exclusión de algún postulante hasta un } \\
\text { día antes de los comicios en caso tome conocimiento de que exista una } \\
\text { condena consentida o ejecutoriada con pena privativa de la libertad. } \\
\text { "De ser condenado Daniel Urresti y, de quedar firme dicha condena (ha- } \\
\text { ber agotado cualquier instancia jurisdiccional, plazos, recursos), podría } \\
\text { ser excluido hasta un día antes del proceso electoral, es decir hasta el } 6 \\
\text { de octubre. En el Caso Bustíos, dudo que dé para una exclusión en esos } \\
\text { términos. La sentencia tendría que ser firme, es decir consentida o ejecu- } \\
\text { toriada", explicó José Tello, especialista en derecho electoral. } \\
\text { sin embargo, Tello precisó que si en caso Urresti resulte elegido y re- } \\
\text { la vacancia. Ello se establece en el artículo } 22 \text { de la Ley Orgánica de } \\
\text { Municipalidades". }\end{array}$ \\
\hline $\begin{array}{l}\text { Palabras } \\
\text { claves }\end{array}$ & $\begin{array}{l}\text { Sentencia condenatoria o ejecutoriada, asesinato, condenado, elecciones, ino- } \\
\text { cente, juicio, absuelto, candidatura, exclusión, cuestionamientos, vacancia. }\end{array}$ \\
\hline rotogral & $\begin{array}{l}\text { "Yo no me pongo en escenarios que para mí no son reales", dijo esta } \\
\text { vez Daniel Urresti confiando en ser absuelto en el juicio por el Caso } \\
\text { Hugo Bustíos. (Foto: El Comercio) }\end{array}$ \\
\hline
\end{tabular}




\begin{tabular}{|c|c|}
\hline $\begin{array}{l}\text { Sentido de la } \\
\text { imagen }\end{array}$ & $\begin{array}{l}\text { La fotografía es de plano medio, esta cuenta con leyenda. Lo que se } \\
\text { quiere evidenciar con el gesto, posición y expresiones corporales (dedo } \\
\text { índice hacia abajo), es que el candidato Daniel Urresti es una persona } \\
\text { autoritaria y que está confiada en que saldrá absuelto el día del juicio, } \\
\text { que es el } 4 \text { de octubre de } 2018 \text {. }\end{array}$ \\
\hline $\begin{array}{c}\text { Mecanismos } \\
\text { utilizados de } \\
\text { posverdad }\end{array}$ & $\begin{array}{l}\text { Desinformación: no se informa en su totalidad sobre el caso Bustíos, } \\
\text { únicamente se menciona brevemente. Más preocupación existe en si Da- } \\
\text { niel Urresti será o no candidato. } \\
\text { Hechos alternativos: el postulante crea argumentos para refutar los datos } \\
\text { reales y evidentes. Es decir, arma sus propias versiones puestas como } \\
\text { verdad, mencionando que el ser declarado culpable no era parte de su } \\
\text { realidad. } \\
\text { Interpretaciones alternativas: existe un solo hecho, sin embargo, están } \\
\text { presentes innumerables interpretaciones. Para unos, este candidato es } \\
\text { inocente, mientras que para otros es culpable por el asesinato del perio- } \\
\text { dista Hugo Bustíos en Ayacucho, en 1988. } \\
\text { Falacias: } \\
\text {-Relevancia: } \\
\text { Pista falsa: la duda de que Daniel Urresti sea inocente o culpable está } \\
\text { presente. Sin embargo, el candidato, a través de sus argumentos ambi- } \\
\text { guos, quiere llamar la atención y convencer a la población de que es } \\
\text { inocente. } \\
\text { El hombre de paja: el postulante Daniel Urresti no sabe si es inocente o } \\
\text { culpable, pero al manifestar su posición de inocencia causa una distor- } \\
\text { sión en la mentalidad de los ciudadanos, haciéndoles creer que es ab- } \\
\text { suelto. } \\
\text {-Inducción deficiente: } \\
\text { Apelación inapropiada a la autoridad: la hipótesis de que Daniel Urresti } \\
\text { sea culpable es una de las opciones que se presentan en la nota. Esta } \\
\text { es respaldada por el especialista en derecho electoral, José Tello, quien } \\
\text { dice que si el postulante recibe una condena consentida o ejecutoriada se } \\
\text { puede pedir su vacancia. } \\
\text {-No se utilizan las falacias de presuposición ni de ambigüedad. }\end{array}$ \\
\hline
\end{tabular}

Nota: Elaboración propia. 


\subsection{Publicación realizada el 28/09/18}

\section{Tabla 2}

\section{Contenido del diario El Comercio}

\begin{tabular}{|c|c|}
\hline Fuente & $\begin{array}{l}\text { https://elcomercio.pe/politica/daniel-urresti-peru-candidatos-piden-in- } \\
\text { vestigar-sancionar-presuntas-firmas-falsas-partido-noticia-562406-noti- } \\
\text { cia/?ref=ecr }\end{array}$ \\
\hline Titular & $\begin{array}{l}\text { "Candidatos piden investigar y sancionar presuntas firmas falsas de Pode- } \\
\text { mos" }\end{array}$ \\
\hline $\begin{array}{l}\text { Sentido del } \\
\text { titular }\end{array}$ & $\begin{array}{l}\text { Evidenciar que el partido Podemos Perú, representado por Daniel Urresti, } \\
\text { está involucrado en un nuevo problema: la falsificación de firmas para su } \\
\text { inscripción. Por lo tanto, los demás candidatos al sillón municipal solicitan } \\
\text { que se le investigue y sancione, si es el caso. }\end{array}$ \\
\hline Bajada & $\begin{array}{l}\text { "Renzo Reggiardo, Humberto Lay, Alberto Beingolea y Gustavo Guerra co- } \\
\text { mentaron la denuncia contra el partido de Daniel Urresti". }\end{array}$ \\
\hline $\begin{array}{l}\text { Sentido de } \\
\text { la bajada }\end{array}$ & $\begin{array}{l}\text { Enfatizar en que la organización política a la que pertenece el candidato Da- } \\
\text { niel Urresti está envuelta en una denuncia de firmas falsas. La finalidad de } \\
\text { esta información es que menos personas, al enterarse de este inconveniente, } \\
\text { voten por él. Por ello, los demás candidatos exponen y publican este tema } \\
\text { constantemente. }\end{array}$ \\
\hline $\begin{array}{l}\text { Cuerpo } \\
\text { de texto }\end{array}$ & $\begin{array}{l}\text { "Diversos candidatos a la alcaldía de la Municipalidad de Lima se pronun- } \\
\text { ciaron para pedir que el Jurado Nacional de Elecciones (JNE) investigue } \\
\text { y sancione la presunta presentación de firmas falsas por parte del partido } \\
\text { Podemos Perú, por el cual está postulando Daniel Urresti. } \\
\text { Renzo Reggiardo, de Perú Patria Segura, acusó a Daniel Urresti de mentir } \\
\text { al indicar que todos los partidos políticos presentan firmas falsas en sus } \\
\text { padrones, los cuales son rechazados por los entes electorales. } \\
\text { "Es absolutamente falso. Han tenido la desgracia que se evidenció su caso } \\
\text { con personas famosas y por eso se ha podido detectar. ¿Imaginan la cantidad } \\
\text { de gente que ha inventado firmas? Esto es un escándalo y el JNE tiene que } \\
\text { decir algo e investigar a profundidad", dijo el candidato en entrevista a ATV. } \\
\text { Renzo Reggiardo cuestionó que el JNE se haya mantenido en silencio desde } \\
\text { que salieron a la luz las primeras críticas hacia el proceso por el cual Po- } \\
\text { demos Perú llegó a inscribirse. "Me parece increíble que el ente electoral } \\
\text { no haya tenido una participación clara al respecto [...] El silencio otorga", } \\
\text { comentó. } \\
\text { Humberto Lay, de Restauración Nacional, fue más allá y pidió, además de } \\
\text { investigaciones, que el JNE suspenda la inscripción de Podemos Perú y que } \\
\text { Daniel Urresti se aparte del proceso electoral. }\end{array}$ \\
\hline
\end{tabular}




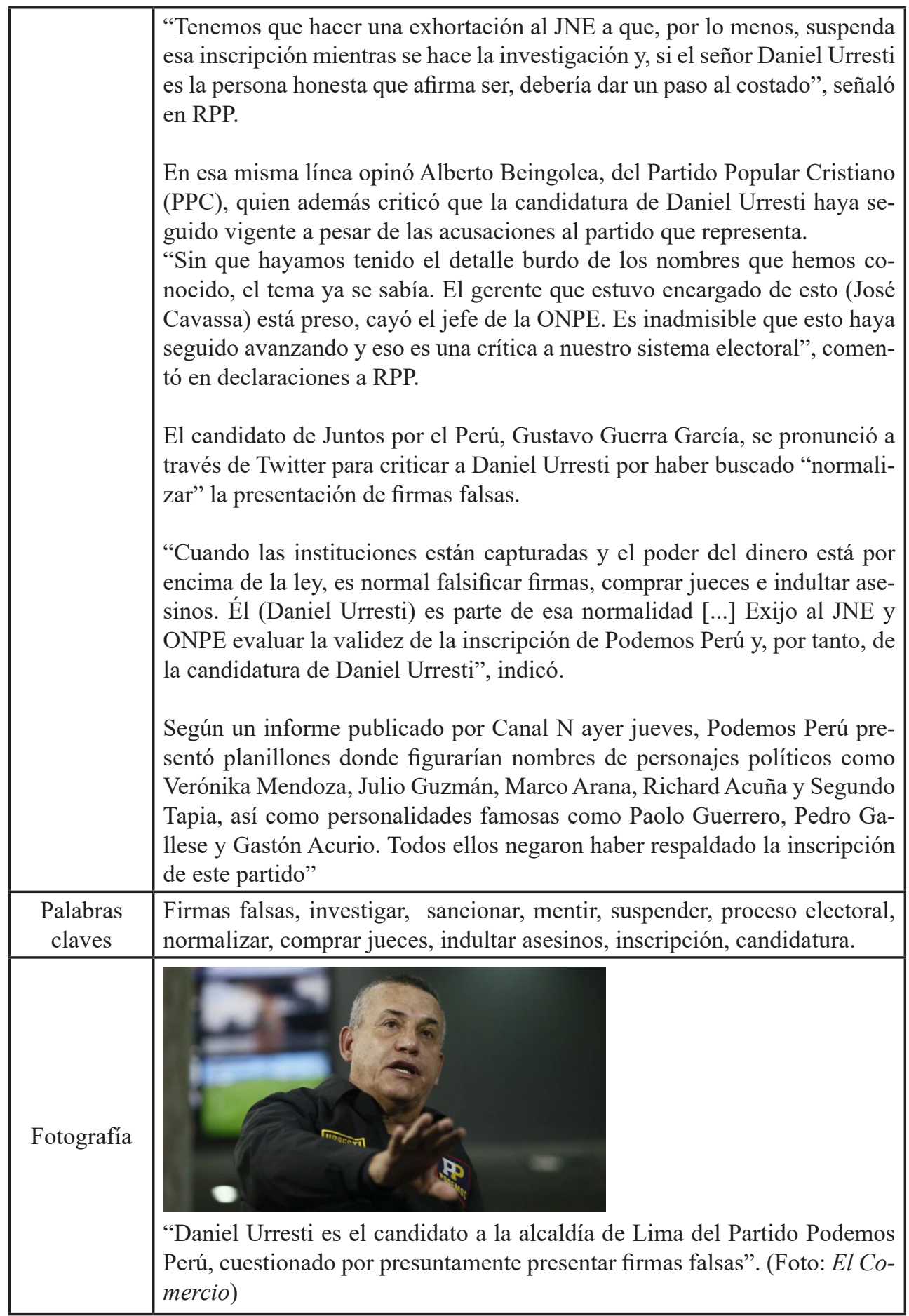




\begin{tabular}{|c|c|}
\hline & $\begin{array}{l}\text { La fotografía es de plano medio corto, esta cuenta con leyenda. Lo que se } \\
\text { quiere evidenciar es que el postulante pertenece a un partido político que } \\
\text { está envuelto en irregularidades en su inscripción, como son las supuestas } \\
\text { firmas falsas. Por ello, se muestra el logo de su organización política en la } \\
\text { casaca del postulante. El gesto, posición y la expresión corporal demuestran } \\
\text { que el candidato normaliza que su partido esté envuelto en temas de falsi- } \\
\text { ficación. }\end{array}$ \\
\hline $\begin{array}{c}\text { Mecanismos } \\
\text { utilizados de } \\
\text { posverdad }\end{array}$ & $\begin{array}{l}\text { Interpretaciones alternativas: el hecho es que el partido de Daniel Urresti } \\
\text { está envuelto en problemas de falsificación de firmas. Sin embargo, existen } \\
\text { diferentes interpretaciones para ese mismo suceso. Para algunos candidatos } \\
\text { se debe investigar el tema, mientras que para otros no solo se debe infor- } \\
\text { mar sino también sancionar severamente con la exclusión del candidato en } \\
\text { cuestión. } \\
\text { Falacias: } \\
\text {-Relevancia: } \\
\text { Argumento ad hominem (ofensivo): el candidato Gustavo Guerra García, } \\
\text { en la nota informativa, menciona que el partido de Daniel Urresti falsifica } \\
\text { firmas, compra jueces e indulta asesinos. Por lo tanto, este postulante está } \\
\text { atacando y difamando directamente a los miembros de Podemos Perú, cuan- } \\
\text { do esto no le consta. } \\
\text {-Inducción deficiente: } \\
\text { Apelación inapropiada a la autoridad: la hipótesis de que la organización } \\
\text { política Podemos Perú esté involucrada en firmas falsas es respaldada por } \\
\text { los diversos candidatos al sillón municipal, como Renzo Reggiardo, Alberto } \\
\text { Beingolea, Gustavo Guerra García y Humberto Lay. } \\
\text {-Presuposición: } \\
\text { Accidente: como el partido de Daniel Urresti está inmerso en un caso de } \\
\text { presuntas firmas falsas, el candidato Gustavo Guerra García generaliza pen- } \\
\text { sando que la organización política, al tener dinero, también compra jueces } \\
\text { e indulta asesinos. } \\
\text {-No se utilizan las falacias de ambigüedad. }\end{array}$ \\
\hline
\end{tabular}

Nota: Elaboración propia. 


\subsection{Publicación realizada el 29/09/18}

\section{Tabla 3}

\section{Contenido del diario El Comercio}

\begin{tabular}{|c|c|}
\hline Fuente & $\begin{array}{l}\text { https://elcomercio.pe/politica/elecciones-2018-partido-daniel-urresti-cues- } \\
\text { tionado-noticia-562696-noticia/?ref=ecr }\end{array}$ \\
\hline Titular & "Elecciones 2018: El partido de Daniel Urresti cuestionado" \\
\hline $\begin{array}{l}\text { Sentido del } \\
\quad \text { titular }\end{array}$ & $\begin{array}{l}\text { Se pone especial énfasis en mencionar que, en la etapa de las elecciones mu- } \\
\text { nicipales, la organización política en la que participaba el candidato Daniel } \\
\text { Urresti estaba en serios cuestionamientos, ya que se creía que existían fir- } \\
\text { mas falsas de diversos personajes públicos en los planillones de su partido. }\end{array}$ \\
\hline Bajada & $\begin{array}{l}\text { "Ante la nueva denuncia vinculada a Podemos Perú, el JNE pidió celeridad } \\
\text { a la fiscalía en la investigación por presuntas irregularidades en su inscrip- } \\
\text { ción" }\end{array}$ \\
\hline $\begin{array}{l}\text { Sentido de } \\
\text { la bajada }\end{array}$ & $\begin{array}{l}\text { Evidenciar que la organización política Podemos Perú, vinculada a Daniel } \\
\text { Urresti, atraviesa problemas como denuncias por las supuestas firmas falsas } \\
\text { que realizó en su inscripción. Esto con la finalidad de intuir que el partido } \\
\text { de Urresti, con estas irregularidades, no es la mejor opción ante la alcaldía } \\
\text { limeña. }\end{array}$ \\
\hline & $\begin{array}{l}\text { "El partido Podemos Perú, que postula a Daniel Urresti a la Alcaldía de Lima y } \\
\text { que lidera el ex congresista José Luna, vuelve a estar en el ojo de la tormenta. } \\
\text { El último jueves, un informe de Canal N dio cuenta de la presunta inclusión } \\
\text { de firmas falsas en los planillones que la agrupación presentó ante la Oficina } \\
\text { Nacional de Procesos Electorales (ONPE) como parte de su proceso de ins- } \\
\text { cripción, el cual culminó con su reconocimiento como organización política } \\
\text { por parte del Jurado Nacional de Elecciones (JNE) en enero pasado. } \\
\text { Según el informe periodístico, en la lista de adherentes presentados por el } \\
\text { partido se incluyó a diversos personajes públicos que dijeron que no habían } \\
\text { firmado los planillones. } \\
\text { En junio de este año, el Ministerio Público ya había iniciado una investi- } \\
\text { gación preliminar a Podemos Perú por las presuntas irregularidades que se } \\
\text { habrían dado en su inscripción. Lo hizo luego de las primeras denuncias } \\
\text { sobre el caso. } \\
\text { El Comercio conoció que el } 5 \text { de setiembre la fiscalía declaró compleja la } \\
\text { investigación y amplió por } 90 \text { días la etapa preliminar. Asimismo, se acu- } \\
\text { muló otro expediente de noviembre pasado referido al hallazgo de presuntas } \\
\text { firmas falsas identificadas por la ONPE durante el proceso de verificación, } \\
\text { antes de la inscripción. }\end{array}$ \\
\hline
\end{tabular}




\begin{abstract}
-Posiciones-
Ayer, a través de un comunicado, el JNE pidió a la fiscalía que agilice su investigación. También le solicitó que tome acciones respecto a los nuevos hechos denunciados.

Desde la ONPE señalaron que la reciente información sobre las presuntas firmas falsas de personajes públicos tuvo como fuente la base de datos de la lista de adherentes presentada en bruto por el partido ante el JNE y no la que fue revisada, depurada y validada por la propia ONPE.

Sobre la última denuncia, el secretario general de Podemos Perú, el ex congresista Enrique Wong, afirmó: "Seguramente al personal que ayudaba a recolectar firmas se le ocurrió inventarlas y sacar datos del Reniec. Estamos identificando a los responsables".

Daniel Urresti indicó a la prensa que "a todos los partidos les pasa lo mismo".

"Para que sea falsificación tiene que imitarse la letra y firma. Acá lo que hubo es la criollada de la gente que rellenó por gusto los planillones", dijo.

-Puntos clave-

1. ¿Cuándo empezaron los cuestionamientos a Podemos Perú?

-A fines de mayo, Susana Guerrero, ex gerenta de Asesoría Jurídica de la ONPE, denunció en "Cuarto poder" un supuesto trato preferente en el ente electoral para el proceso de inscripción del partido. Este fue oficializado como tal por el JNE en enero del presente año.

2. ¿En qué consistió la denuncia?

-La ONPE habría admitido planillones de firmas de adherentes con espacios en blanco no anulados, pese a que esto no está permitido, para evitar manipulaciones. Por el caso, Adolfo Castillo fue suspendido como jefe de la entidad por el ahora desactivado Consejo Nacional de la Magistratura.

3. ¿Se podría anular la inscripción de la organización política?

La Ley de Organizaciones Políticas no contempla que un partido pierda su registro o sea declarado ilegal por fraude en su inscripción. José Tello, especialista en derecho electoral, dijo que sí podría haber responsabilidad administrativa, civil e incluso penal en funcionarios involucrados.
\end{abstract}




\begin{tabular}{|c|c|}
\hline & $\begin{array}{l}\text { 4. ¿Qué podría pasar con la candidatura de Daniel Urresti a la Alcaldía de } \\
\text { Lima? } \\
\text {-En línea con lo anterior, Tello consideró que el caso no afecta a los can- } \\
\text { didatos del partido en los actuales comicios. De ser elegidos, primaría la } \\
\text { voluntad popular y el derecho a ser elegido" }\end{array}$ \\
\hline $\begin{array}{c}\text { Palabras } \\
\text { claves }\end{array}$ & $\begin{array}{l}\text { Adherentes, presuntas irregularidades, denuncias, firmas falsas, inventarlas, } \\
\text { falsificación, cuestionamientos, espacios en blanco no anulados, manipula- } \\
\text { ciones, ilegal, fraude. }\end{array}$ \\
\hline \multicolumn{2}{|l|}{ Fotografía } \\
\hline & $\begin{array}{l}\text { "Daniel Urresti es el candidato a la Alcaldía de Lima de Podemos por el } \\
\text { Progreso del Perú, como se llama oficialmente el partido". (Foto: El Co- } \\
\text { mercio) }\end{array}$ \\
\hline $\begin{array}{l}\text { Sentido de } \\
\text { la imagen }\end{array}$ & $\begin{array}{l}\text { La fotografía es de plano medio corto, esta cuenta con leyenda. Lo que se } \\
\text { quiere evidenciar es que el candidato pertenece a un partido político que } \\
\text { está envuelto en irregularidades en su inscripción. Por ello, se muestra el } \\
\text { logo de su partido en el polo del postulante, así como en los carteles que } \\
\text { llevan las demás personas. El gesto y la posición que demuestra el candidato } \\
\text { es de sorprendido, al ver que el diario le está tomando una fotografía. }\end{array}$ \\
\hline \multirow{2}{*}{$\begin{array}{l}\text { Mecanismos } \\
\text { utilizados de } \\
\text { posverdad }\end{array}$} & $\begin{array}{l}\text { Desinformación: en la nota informativa se puede ver que se informa sobre } \\
\text { las irregularidades que ha cometido el partido político Podemos Perú, rela- } \\
\text { cionándolo con el aspirante al sillón municipal, Daniel Urresti. Sin embar- } \\
\text { go, no se informa, en su totalidad, acerca de los impases que ha cometido } \\
\text { esta organización, ya que es necesario que la ciudadanía los conozca. }\end{array}$ \\
\hline & $\begin{array}{l}\text { Hechos alternativos: el secretario general de Podemos Perú minimizó el } \\
\text { hecho de las firmas falsas, comentando que su personal probablemente in- } \\
\text { ventó las firmas sacando datos de Reniec. Es decir, para no conocer la "ver- } \\
\text { dad" que evidencian los hechos comprobables, utilizan manifestaciones de } \\
\text { las personas como alternativas para intentar contrarrestar lo que se muestra. }\end{array}$ \\
\hline
\end{tabular}




\begin{abstract}
Falacias:
-Relevancia:

Pista falsa: el pensamiento correcto de que el partido por el que postula Daniel Urresti ha incurrido en irregularidades se ve distorsionado por la intromisión del secretario general de esa organización política, ya que manifiesta que las firmas presentes son fruto del personal que las inventó y las llenó en los planillones.

Argumento ad hominem (circunstancial): el ataque que se le quiere hacer al candidato Daniel Urresti es indirecto, relacionándolo con un partido poco confiable. Sin embargo, los defensores de tal organización política siguen sosteniendo que se recurrió a realizar firmas de personajes públicos sin la intención de falsificarlas. De esta manera, los miembros del partido quieren desligarse de toda responsabilidad por tener intereses especiales.

-Inducción deficiente:

Apelación inapropiada a la autoridad: el diario El Comercio apoya la hipótesis que el partido de Urresti es cuestionado por presuntas firmas falsas. Para ello, cita a un especialista en derecho electoral, el cual manifiesta que los funcionarios involucrados en esta falsificación sí podrían estar sancionados de manera administrativa, civil y penal.

Causa falsa: el diario El Comercio quiere demostrar que, a pesar de que el partido de Daniel Urresti está involucrado en irregularidades, el candidato tiene la potestad de seguir siendo elector en donde se priorice la voluntad popular y el derecho a ser elegido. Por ello, este medio quiere concientizar a los electores para que conozcan qué candidato es el ideal para que sea alcalde de Lima. Como se puede analizar, la causa de ser candidato conocido no es motivo de que el partido de Daniel Urresti esté fuera de los comicios por estar cuestionado en la falsificación de firmas falsas. Son dos acciones en una sucesión de tiempo distintas.

-No se utilizan las falacias de presuposición ni de ambigüedad.
\end{abstract}

Nota: Elaboración propia.

\title{
5. Discusión
}

Nota informativa 1: Los resultados obtenidos confirman y amplían la teoría expuesta, ya que la desinformación, los hechos alternativos, las interpretaciones alternativas y las falacias de relevancia e inducción deficiente, se desarrollan dentro del fenómeno de la posverdad. Por ejemplo, según el diccionario de Oxford, los hechos objetivos influencian menos que los que se basan en 
las emociones o creencias personales. Por lo tanto, el caso de Hugo Bustíos es importante y constantemente expuesto por los medios, porque juega con los sentimientos de los ciudadanos, ya que está poniéndose en tela de juicio si el candidato es inocente o culpable. Sin embargo, el tipo de discurso que realiza el medio indica que lo realizado por el exministro respecto al caso en cuestión es cuestionable y hasta criticable.

Nota informativa 2: Los resultados obtenidos confirman y amplían la teoría expuesta, ya que las interpretaciones alternativas y las falacias de relevancia, inducción deficiente y presuposición, se desenvuelven en el periodismo político. Además, para Héctor Béjar por ejemplo, los medios quieren generar en los lectores pensamientos y opiniones que beneficien a tal periódico. Es decir, construyen ideologías para definir lo que es aceptable o rechazable. Por lo tanto, utilizan palabras clave para criticar la candidatura de Daniel Urresti en las elecciones municipales pasadas.

Nota informativa 3: Los resultados obtenidos confirman la teoría expuesta, ya que la desinformación, los hechos alternativos y las falacias de relevancia e inducción deficiente se desenvuelven en el periodismo político. Asimismo, para Andreu Casero, los periodistas están limitados al ejercicio de sus funciones, porque dependen de lo que el medio desee exponer. Por ello, recurren a mecanismos de posverdad. Por su lado, para Daniel Morán y María Isabel Aguirre, los periodistas elaboran sus redacciones según la afinidad que tienen respecto al tema publicable. Por ende, el discurso que informa sobre firmas falsas de personajes públicos en los planillones del partido Podemos Perú, busca generar interés y apoyo a la clase social a la que pertenece. En otras palabras, se quiere criticar a esta organización política por la irregularidad hecha.

\section{Conclusiones}

En primer lugar, si bien el estilo de redacción de las notas de El Comercio sobre Daniel Urresti está bien cuidado para dar la apariencia de equilibrio informativo, una lectura atenta que privilegie categorías discursivas o palabras clave, evidencia que son más bien críticas y expresarían así la posición ideológica del diario. Las principales palabras clave fueron: sanción, sentencia, culpable, asesinato, condenado, candidatura, exclusión, cuestionamientos, vacancia, proceso electoral, firmas falsas, ilegal, fraude, entre otras. 
En segundo lugar, el medio digital El Comercio, a diferencia de lo que sucede con otros candidatos a la alcaldía de Lima, hace un especial énfasis en resaltar el juicio que atravesaba Daniel Urresti. Esto con la intención de demostrar que el postulante, ante el asesinato de Hugo Bustíos, podía ser culpable y que, por lo tanto, no era seguro votar por una persona que podía tener parte de responsabilidad en ello.

En tercer lugar, el diario El Comercio mostraba en sus notas informativas fotografías que no beneficiaban al candidato Daniel Urresti, pues en la mayoría el postulante sale con una expresión que no ayudaría a que voten por él. Se le veía como una persona alejada, apagada, nerviosa, preocupada y autoritaria. Además, las leyendas de las imágenes terminaban por confirmar lo que transmitía la foto: se contaba lo negativo de él o muchas veces se informaba dejando al lector pensativo.

En cuarto lugar, la crítica periodística que realizó El Comercio resaltaba constantemente el entorno que tenía el candidato Daniel Urresti para sobrellevar una candidatura municipal. Por ejemplo, el que su partido político Podemos Perú esté inmerso en la falsificación de firmas falsas en sus planillones, hace que se crea que esa organización no es la adecuada para votar por ella.

En quinto lugar, el medio digital El Comercio utilizó los siguientes mecanismos de posverdad: la desinformación, los hechos alternativos, las interpretaciones alternativas y las heterogéneas falacias para crear un mal concepto del candidato en cuestión.

\section{Fuentes consultadas}

Adrianzén, Alberto et al. (2008). Manipulación ideológica y poder. En: Poder mediático (pp.25-36). Universidad de Ciencias y Humanidades.

Barrios, A., \& Hernández, F. (2011). El rol de las campañas electorales y los medios de comunicación en un proceso electoral equitativo. En Construyendo las condiciones de equidad en los procesos electorales (pp.123-146). IIDH. 
Béjar, Héctor et al. (2008). Poder mediático y manipulación ideológica. En Poder mediático (pp.10-24). Universidad de Ciencias y Humanidades.

Califano, B. (2015). Los medios de comunicación, las noticias y su influencia sobre el sistema político. Revista mexicana de opinión pública, (19), 61-79. https://doi.org/10.1016/j.rmop.2015.02.001

Casero-Ripolles, A. (2012) El periodismo político en España: algunas características definitorias. La Laguna: Sociedad Latina de Comunicación Social, 19-46. http://repositori.uji.es/xmlui/bitstream/handle/10234/80553/Casero_19_46.pdf?sequence

Clavero, J. (2018). Posverdad y exposición selectiva a fake news. Algunos ejemplos concretos de Argentina. Contratexto, (29), 167-180. https:// hdl.handle.net/20.500.12724/6414

Copi, I., \& Cohen, C. (2013). Introducción a la lógica. Limusa.

Feal Vázquez, J. (2004). El poder mediático. Boletín de información, (283), 4.

Fowks, J. (2017). Mecanismos de la posverdad. Fondo de Cultura Económica.

Frápolli, J. \& Nicolás, J. (1997). Teorías de la verdad en el siglo XX. [Archivo PDF]. https://es.scribd.com/document/343655697/Teorias-De-LaVerdad-En-El-Siglo-XX-pdf

Fundación Gabo (3 de diciembre de 2019). Javier Darío Restrepo, periodismo y pasión: Interrogantes sobre el ejercicio y la ética profesional. https://fundaciongabo.org/es/etica-periodistica/recursos/las-100-mejores-frases-de-javier-dario-restrepo-sobre-etica-periodistica

García, J. (2009). El rol de los medios de comunicación durante los procesos electorales [Archivo PDF]. https://www.oas.org/sap/docs/ DECO/7_EMBs/presentaciones/Presentaci\%C3\%B3n\%20Garc\%C3\%ADa\%20Rodr\%C3\%ADguez\%20ESPA\%C3\%91OL.pdf

González, M. (2017, 06). La «posverdad» en el plebiscito por la paz en Colombia. [Archivo PDF]. https://biblat.unam.mx/hevila/Nuevasociedad/2017/no269/13.pdf 
Gutiérrez, S. (2010). Discurso Periodístico: una propuesta analítica. Nueva época, (14), 169-198. http://www.scielo.org.mx/scielo.php?script=sci_arttext\&pid=S0188-252X2010000200007

Kovach, B. \& Rosenstiel, T. (2003). Los elementos del periodismo. Aguilar.

Mittermeier, J. (2017). Desmontando la posverdad. Nuevo escenario de las relaciones entre la política y la comunicación [Tesis de maestría]. Universidad Autónoma de Barcelona. https://ddd.uab.cat/pub/trerecpro/2017/hdl_2072_293810/TFM_Johanna_Mittermeier.pdf

Morán, D., \& Aguirre, M. (2014). La prensa y el discurso político en la historia peruana: algunas consideraciones teóricas y metodológicas. Investigaciones Sociales, 12(20), 229-248. https://doi.org/10.15381/ is.v12i20.7179

Moreno, P. (2000). Los géneros periodísticos informativos en la actualidad internacional. Ámbitos, (5), 169-190. https://idus.us.es/bitstream/ handle/11441/12708/file_1.pdf?sequence=1\&isAllowed=y

Oxford Dictionarie, 2016. https://www.oed.com

Van Dijk, T. (1990). La noticia como discurso. Comprensión, estructura y producción de la información. Paidós.

Van Dijk, T. (2005). Política, ideología y discurso. Zulia.

Van Dijk, T. (2009). Discurso y poder. Gedisa. 